\title{
Students' Perceptions of Simulation-Based Learning in Speech Pathology: A Pilot Study
}

\author{
*Adriana Penman ${ }^{a}$, Anne E. Hill ${ }^{a}$, Sally Hewat ${ }^{b}$, and Nerina Scarinci ${ }^{a}$ \\ a: The University of Queensland, Australia, $b$ : The University of Newcastle, Australia
}

\begin{abstract}
Due to increased student numbers and workforce limitations, speech pathology students have fewer opportunities to develop skills in working with adult populations in traditional clinical placements. Using simulation-based learning has proven to be advantageous in other disciplines. The use of simulation to develop clinical skills in speech pathology range of practice areas, including speech, language and swallowing in adults, has been less well researched. The aim of this study was to investigate students' overall perceptions about simulation-based learning, particularly their confidence related to specific clinical skills and perceived anxiety about working with adult clients. Six final year speech pathology students enrolled in either a 4-year undergraduate or 2.5-year masters program participated in this research. Students engaged in five simulation-based learning activities across one day. Purposefully developed pre- and post- surveys were completed to explore students' anxiety levels and perceptions of confidence regarding clinical skills across domains of foundation knowledge, case history, assessment, intervention, interaction and clinical reasoning, and anxiety levels. The Satisfaction with Simulation Experience (SSE) Scale was completed postsimulation experience. Students also participated in a focus group discussion following the simulation experience. Student median ratings of clinical skills improved from pre- to postsimulation across the six domains. All students reported that the simulation-based learning experience was valuable and reported increased levels of confidence and enhanced preparedness for their clinical placements. Findings from this study suggested that students value simulationbased learning and future research should explore learning outcomes from a longer, more intensive simulation program.
\end{abstract}

Keywords: clinical education; simulation; simulation-based learning; speech pathology; student learning

\section{Introduction}

Speech pathologists are health professionals competent in the diagnosis, management and treatment of individuals who are unable to communicate effectively, or who have difficulty with feeding and swallowing (Speech Pathology Association of Australia [SPAA], 2010). Speech pathology students trained in Australian universities are required to attain entry-level competency standards at the completion of their program as defined by the profession's Competency-Based Occupational Standards for Speech Pathologists - Entry Level (CBOS) (SPAA, 2011). University programs are therefore accredited by Speech Pathology Australia on the

*Corresponding Author: Adriana Penman, School of Health and Rehabilitation Sciences, Faculty of Health and Behavioural Sciences, The University of Queensland, Australia Email: a.penman1@uq.edu.au

Journal URL: https://publications.coventry.ac.uk/index.php/pblh

Penman, A., Hill, A. E., Hewat, S., \& Scarinci, N. (2020). Students' perceptions of simulation-based learning in Speech Pathology: A pilot study. International Journal of Practice-based Learning in Health and Social Care, 8(1), 1-14. https://doi.org/10.18552/ijpblhsc.v8i1.558

\section{(c) $(\$)$}

(C) 2020 Adriana Penman, Anne E. Hill, Sally Hewat, Nerina Scarinci. This Open Access article is distributed under the terms of the Creative Commons Attribution Attribution-Non-Commercial No Derivatives 4.0 International License (https://creativecommons.org/licenses/by-nc-nd/4.0/ ), which permits unrestricted noncommercial use, distribution, and reproduction in any medium, provided the original work is properly cited and is unaltered. 
basis that all students can demonstrate entry-level competency in practice with both adult and paediatric populations.

In order to meet professional competency standards, clinical placements encompass a significant component of speech pathology program curricula. Without the opportunity to engage in the experiential learning that clinical placements provide, students may have difficulty applying theoretical knowledge to real-world practices and in transferring their skills into clinical settings (Higgs \& Titchen, 2001; Sheepway et al., 2011). However, in the tertiary sector the provision of quality clinical education has gradually become more challenging (Kelly et al., 2016; Sheepway et al., 2011). These challenges are based around the increased demands placed on clinical staff, limited resources, and the rapid increase in speech pathology students requiring clinical placements (MacBean et al., 2013; Speech Pathology Australia, 2018). Combined with changes in workplace environments and speech pathology scope of practice, this growing trend has made it even more difficult for students to gain experience and develop competency in managing both adults and children with diverse communication or swallowing difficulties. With fewer opportunities for clinical skill development in traditional settings, university programs have been required to consider other positive and economically viable clinical learning experiences (Sheepway et al., 2011). One trend which has continued to gain momentum within health care education is simulation-based learning (Kelly et al., 2016).

Simulation involves the imitation of real-world processes and the recreation of a clinical experience whilst encompassing both the cognitive and affective domains (Ker \& Bradley, 2014). Similar to clinical experiences with real patients, students learn by doing (Kolb \& Kolb, 2005); however, in a simulated learning environment, standardised or simulated patients are used. Standardised patients are patients who have been chosen to convey a particular diagnosis or persona in a standardised manner (Ker, \& Bradley, 2014). Simulated patients are trained actors imitating the qualities of a patient (Barrows, 1993). These terms are used interchangeably in the literature. Simulation provides an opportunity for students to learn in a safe, education-rich environment where they are able to reflect, refine, and then repeat, to advance their clinical skills (Kelly et al., 2016; Ker \& Bradley, 2014). In simulation-based learning activities, students apply their knowledge to practice, and develop critical thinking and reasoning skills (Meakim et al., 2013; Wallace \& Moughrabi, 2016).

Positive learning outcomes from simulation have been reported for health science students for many decades, firstly within medical programs (Barrows, 1993; Lateef, 2010) and then more recently with other health science education programs such as nursing and physiotherapy (Blackstock et al., 2013; Hayden et al., 2014; Watson et al., 2012). Preliminary investigations of speech pathology simulation-based learning in the Australian context highlighted the potential of simulation as an effective teaching method in conjunction with traditional clinical placements (MacBean et al., 2013). Recently, in the United States, Dudding and Nottingham concluded that with the emerging acceptance of simulation as a viable education tool, research regarding the most appropriate application of simulation-based learning into clinical training of speech pathology students was needed (Dudding \& Nottingham, 2018).

Studies in speech pathology have demonstrated that simulation improves students' perceived confidence in their communication and professional skills (Hill et al., 2013), working in an acute care environment (Rose et al., 2017) and dysphagia skills (Ward et al., 2015). Additionally, the results of a study investigating an interprofessional approach to simulation-based dysphagia training of speech pathology and dietitian students revealed an increase in students' perceived confidence, knowledge and preparedness and general acceptance of this learning modality by students (Miles et al., 2016). Furthermore, a study exploring the benefits of simulation activities using high-fidelity mannequins with speech pathologists, inexperienced in tracheostomy management, led to improved manual and core task performance skills as well as a perceived increase in their confidence (Ward et al., 2014). Taken together, this research highlights the value of simulation and shows that a simulated environment can provide successful learning experiences within speech pathology education and practice. However, the application of simulation is currently limited in scope. Research has not yet examined the impact of simulation-based learning within an adult caseload presenting with a myriad of communication and swallowing difficulties.

Therefore, in response to a shortage of clinical placements within the Australian speech pathology workforce, a national speech pathology collaborative was awarded funding by the Australian Government Department of Health in 2014 under the Embedding Simulation in Clinical Training in Speech Pathology project to investigate the viability of replacing traditional clinical placement time in adult practice with a simulation-based learning program. During the development phase of a five-day simulation-based learning program to support student competency development in adult speech pathology range of practice areas (Hewat et al., in press), the current one-day pilot study was implemented with the intention of informing program content and structure prior to full 
implementation. Therefore, the aim of this study was to determine students' perceptions of a one-day simulation-based learning experience focussed on adult speech pathology practice, their confidence related to specific clinical skills, and their anxiety levels following participation in the simulation experience.

\section{Method}

\section{Participants}

Six final-year speech pathology students participated in this pilot study, with four enrolled in a 4-year undergraduate program and two enrolled in a 2.5-year graduate-entry masters program. Students' ages ranged from 20 to 38 years $(M=25.5$ years). Five students were female, reflective of the speech pathology workforce (Health Workforce Australia, 2014). Students had comparable academic content, clinical placements and experience in simulation-based learning activities (parent interviews, voice management) within their speech pathology programs prior to the study.

\section{Study design}

This study used a simultaneous mixed methods approach (Creswell \& Plano Clark, 2011). Quantitative data was obtained via completion of a survey pre- and post-simulation-based learning activities, and qualitative data was collected via a participant focus group at the end of the one-day simulation experience. The use of focus groups in conjunction with quantitative data provides opportunity for deeper understanding and insights related to a topic (Khan et al., 1991).

\section{Procedure}

Ethical clearance for this study was obtained through the University of Queensland Human Research Ethics Committee (approval number 2014001462). Prior to the study, all final-year undergraduate and graduate entry masters speech pathology students were invited via email to participate in this voluntary additional learning experience. Sixteen students indicated interest; due to the timing of the pilot study, however, six students participated.

The simulation-based learning activities included in the pilot were selected from the proposed five-day simulation program (Hewat et al., in press). The activities chosen aimed to develop students' clinical skills related to communication, interviewing, gathering case history information, assessment, intervention, and clinical reasoning when working with adults presenting with a communication and/or swallowing disorder.

Students engaged in five simulated learning activities that involved various teaching and learning modalities. For example, through the use of pause-discuss methodology (Nestel \& Bearman, 2014), the first simulated learning activity was paused to facilitate explicit teaching and further discussion. All simulation activities included three phases considered essential to the simulation learning process: pre-brief, simulation activity, and debrief (Fenwick \& Dahlgren, 2015; Kelly et al., 2016; Ker \& Bradley, 2014; Page-Cutrara \& Turk, 2017). Details of all simulation activities are provided in Table 1.

A standard university teaching room was reconfigured to simulate: (1) an acute hospital room with a standard hospital bed and typical materials and equipment found in this setting, and (2) a speech pathology outpatient clinic room (or office). Another smaller, adjacent teaching room was used as a 'break-out' room for the pre-brief and debrief of simulation activities. Four simulated patients portrayed a total of five cases across the day (see Table 1), with training provided to facilitate accurate case portrayal.

An experienced clinical educator and speech pathologist (first author) facilitated the students' learning during the pre-brief, simulation activity, and debrief. Following procedures described by Hill et al. (2010) simulated patients also provided feedback to the students after three of the simulation-based learning activities. Students were involved in all learning experiences taking the role of either a student clinician, the patient or an observer. They noted peer observations and completed reflections following each learning experience. 
Table 1. Structure of simulated-based learning experiences

\begin{tabular}{|c|c|c|c|c|c|c|}
\hline Simulation & Case details & Environment & Clinical activity & $\begin{array}{l}\text { Mode of } \\
\text { simulation }\end{array}$ & $\begin{array}{c}\text { Clinical } \\
\text { educator : } \\
\text { student ratio }\end{array}$ & Feedback \\
\hline 1 & $\begin{array}{l}66 \text { year old female } \\
\text { post left hemisphere } \\
\text { stroke }\end{array}$ & $\begin{array}{l}\text { Acute hospital care } \\
\text { Single bed room - } \\
\text { daughter present for } \\
\text { assessment }\end{array}$ & $\begin{array}{l}\text { Initial clinical swallowing } \\
\text { examination (CSE) and } \\
\text { communication } \\
\text { assessment } \\
\text { Provision of assessment } \\
\text { findings to nursing staff }\end{array}$ & Pause-discuss & $1: 6$ & $\begin{array}{l}\text { Simulated } \\
\text { patient and } \\
\text { clinical educator }\end{array}$ \\
\hline 2 & $\begin{array}{l}35 \text { year old female } \\
\text { with a diagnosis of } \\
\text { multiple sclerosis }\end{array}$ & $\begin{array}{l}\text { Acute hospital care } \\
\text { Multi-bed room }\end{array}$ & $\begin{array}{l}\text { Communication screen } \\
\text { and CSE }\end{array}$ & Role-play* & $1: 2 * *$ & Clinical educator \\
\hline 3 & $\begin{array}{l}45 \text { year old female } \\
\text { with a diagnosis of } \\
\text { a brain tumour }\end{array}$ & $\begin{array}{l}\text { Acute hospital care } \\
\text { Single bed room }\end{array}$ & $\begin{array}{l}\text { Pre-operative } \\
\text { communication and } \\
\text { language assessment } \\
\text { Discussion of post- } \\
\text { operative care }\end{array}$ & Peer observation & $1: 2 * *$ & $\begin{array}{l}\text { Peer and clinical } \\
\text { educator }\end{array}$ \\
\hline 4 & $\begin{array}{l}65 \text { year old male } \\
\text { post left hemisphere } \\
\text { stroke }\end{array}$ & $\begin{array}{l}\text { Rehabilitation inpatient } \\
\text { setting } \\
\text { Speech pathology } \\
\text { office }\end{array}$ & $\begin{array}{l}\text { Expressive language } \\
\text { initial treatment session }\end{array}$ & $\begin{array}{l}\text { Peer observation, } \\
\text { reflection and } \\
\text { practice }\end{array}$ & $1: 2 * *$ & $\begin{array}{l}\text { Simulated } \\
\text { patient and peer }\end{array}$ \\
\hline 5 & $\begin{array}{l}70 \text { year old male } \\
\text { post urinary tract } \\
\text { infection; } 60 \text { year } \\
\text { old female } \\
\text { (patient's wife) }\end{array}$ & $\begin{array}{l}\text { Speech pathology } \\
\text { office }\end{array}$ & $\begin{array}{l}\text { Patient education } \\
\text { regarding swallow safety } \\
\text { requirements on a } \\
\text { modified diet }\end{array}$ & $\begin{array}{l}\text { Simulation-based } \\
\text { learning activity }\end{array}$ & $1: 2 * *$ & $\begin{array}{l}\text { Simulated } \\
\text { patient and } \\
\text { clinical educator }\end{array}$ \\
\hline
\end{tabular}

*In the role-play simulation, one student assumed the role of the student clinician whilst the other student was acting as a simulated patient

**During these simulations, students worked in pairs with the remaining students as observers 


\section{Data collection tools}

Quantitative data. All students completed a purposefully developed pre- and post-simulation survey investigating their perceived confidence in seven clinical skills and their perceived levels of anxiety. These surveys were developed specifically for the five-day simulation-based learning program. Survey items were based on a literature review of critical skills believed to develop in a simulation-based learning environment,

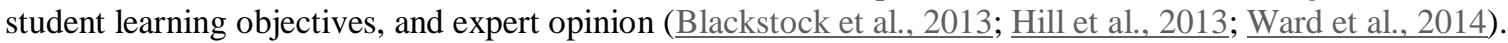

The pre-simulation survey included demographic information, students' self-ratings, clinical placement aspirations, and survey development feedback. In the pre- and post-simulation surveys items in the self-rating section were rated on a five-point Likert scale ranging from $1=$ not confident to $5=$ extremely confident. Students rated their confidence levels with regards to foundation skills such as their use of non-verbal and verbal communication skills, time management and professional skills (11 questions), case-history taking skills (7 questions), assessment skills (4 questions), intervention skills (6 questions), and interaction skills (6 questions). Students also rated their overall clinical reasoning skills and their perceived overall anxiety levels $(1=$ not anxious to $5=$ extremely anxious) when working with an adult population.

In addition to the above information, the post-simulation survey also included the Satisfaction with Simulation Experience (SSE) Scale (Levett-Jones et al., 2011). Students indicated their level of agreement related to: (1) debrief and reflection, (2) clinical reasoning, and (3) clinical learning across eighteen statements using a fivepoint Likert scale ranging from strongly disagree to strongly agree.

Qualitative data. Further insights from students regarding the simulation experience were obtained through participation in a semi-structured focus group at the conclusion of the one-day simulation experience. A researcher (third author) not directly involved as a clinical educator in the pilot study facilitated this. Students were asked to comment on their experience with simulation generally and then, more specifically, their perceptions related to the simulation-based learning activities. In particular, the focus group explored information regarding the timing, authenticity, modes of simulation, simulated patients, and overall structure and learning process within simulation. The focus-group interview was 38 minutes in duration, audio recorded and transcribed verbatim by the first author for analysis.

\section{Data analysis}

Survey data was entered into Microsoft Excel and analysed using descriptive statistics (median and range). Focus group transcripts were analysed using qualitative content analysis, according to the process described by Graneheim and Lundman (2004). Meaning units of the responses were extracted, reduced into condensed meaning units and then labelled into codes. All related codes were grouped into sub-categories and categories (Graneheim \& Lundman, 2004). Coding was originally conducted by the principal investigator and reviewed by co-authors to ensure meaningful interpretation of the data and to increase the rigour of data analysis. Consensus was reached during this process.

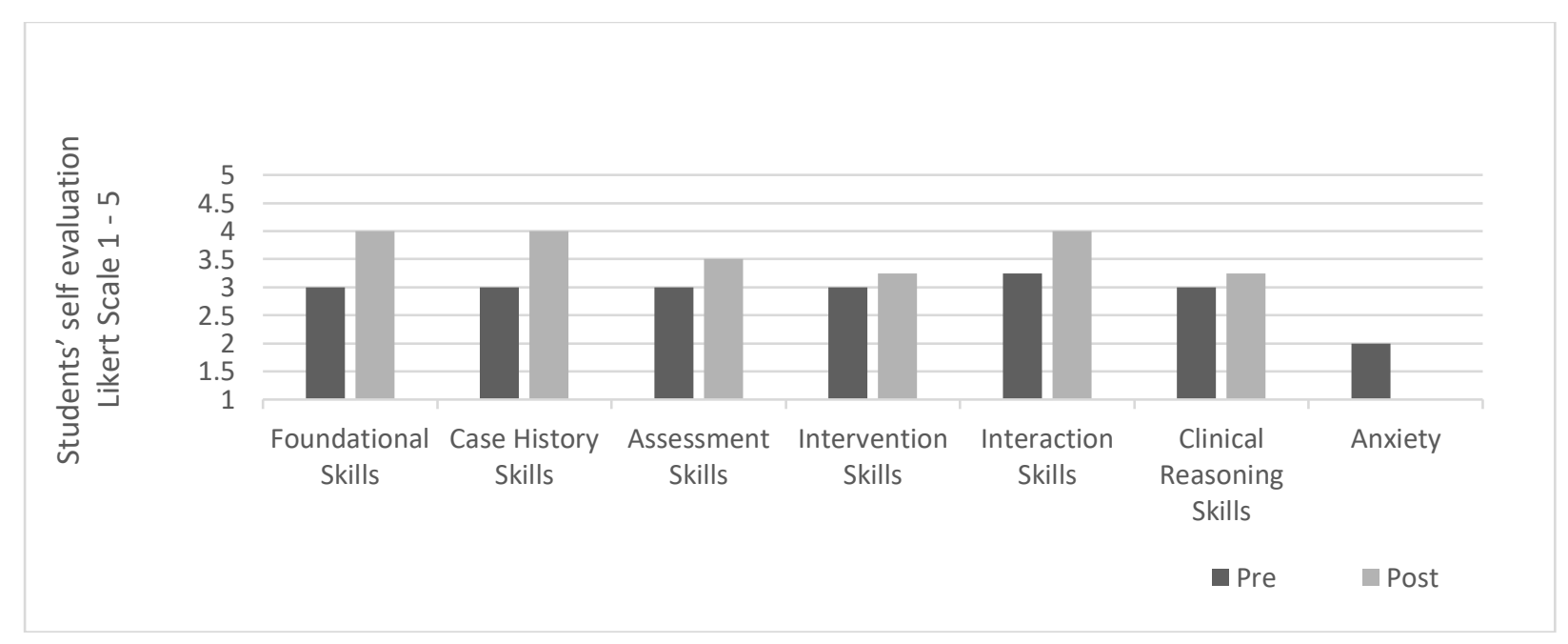

Figure 1. Median results of pre- and post-simulation-based learning survey responses (Note: Post-Anxiety = 0) 


\section{Results}

Analysis of the pre- and post-simulation survey responses indicated increased self-ratings across the two time points for perceived confidence levels for the domains of foundation, case history, assessment, intervention, interaction and clinical reasoning skills (refer to Figure 1). The greatest median change from 3 (moderately confident) to 4 (very confident) was reported in foundation skills (e.g., ability to develop rapport, and avoid jargon in explanations) and case history skills. Students' perceived anxiety levels decreased from a median score of 2 (range 1-5) to 1 (range 1-2). Following the simulation experience, ratings of anxiety levels for all students were at either not anxious $(n=4)$ or slightly anxious $(n=2)$ levels.

Student responses on the SSE scale (Levett-Jones et al., 2011) indicated a high level of agreement (median 5) for all items related to debrief, reflection and clinical learning. A median score of 4.1 was obtained for responses related to clinical reasoning (refer to Table 2). All students strongly agreed that the simulation was a valuable learning experience (item 14).

Table 2. Summary of student responses on the Satisfaction with Simulation Experience Scale (Levett-Jones et al. 2011)

\begin{tabular}{|c|c|c|}
\hline & Median & Range \\
\hline \multicolumn{3}{|l|}{ Debrief and reflection } \\
\hline 1. The facilitator provided constructive criticism during the debriefing & 5 & 5 \\
\hline 2. The facilitator summarised important issues during the debriefing & 5 & 5 \\
\hline $\begin{array}{l}\text { 3. I had the opportunity to reflect on and discuss my performance during } \\
\text { the debriefing }\end{array}$ & 5 & $4-5$ \\
\hline 4. The debriefing provided an opportunity to ask questions & 5 & 5 \\
\hline $\begin{array}{l}\text { 5. The facilitator provided feedback that helped me to develop my clinical } \\
\text { reasoning skills }\end{array}$ & 5 & 5 \\
\hline 6. Reflecting on and discussing the simulation enhanced my learning & 5 & 5 \\
\hline 7. The facilitator's questions helped me to learn & 5 & $4-5$ \\
\hline 8. I received feedback during the debriefing that helped me to learn & 5 & 5 \\
\hline $\begin{array}{l}\text { 9. The facilitator made me feel comfortable and at ease during the } \\
\text { debriefing }\end{array}$ & 5 & 5 \\
\hline \multicolumn{3}{|l|}{ Clinical reasoning } \\
\hline 10. The simulation developed my clinical reasoning skills & 4 & $4-5$ \\
\hline 11. The simulation developed my clinical decision-making ability & 4 & $4-5$ \\
\hline 12. The simulation enabled me to demonstrate my clinical-reasoning skills & 4 & $4-5$ \\
\hline 13. The simulation helped me to recognise patient deterioration early & 3.5 & $3-4$ \\
\hline 14. This was a valuable learning experience & 5 & 5 \\
\hline \multicolumn{3}{|l|}{ Clinical learning } \\
\hline 15. The simulation caused me to reflect on my clinical ability & 5 & 5 \\
\hline 16. The simulation tests my clinical ability & 5 & 5 \\
\hline 17. The simulation helped me to apply what I learned from the case study & 5 & $4-5$ \\
\hline $\begin{array}{l}\text { 18. The simulation helped me to recognize my clinical strengths and } \\
\text { weaknesses }\end{array}$ & 5 & 5 \\
\hline
\end{tabular}

Note: 1 = strongly disagree, 2 = disagree, 3 = unsure, 4 = agree, 5 = strongly agree

Analysis of the qualitative focus group data revealed 199 condensed meaning units, which were assigned and labelled into 113 codes. These codes were collapsed and final consensus reached on 87 codes which were grouped into 18 sub-categories. Six main categories were generated from this data: (1) simulation creates opportunities to learn; (2) simulation provides a beneficial transition for students; (3) simulation provides holistic reflection and feedback; (4) students place value on realism in simulation; (5) students are invested in simulation; and (6) simulation requires consideration of timing and preparation (see Table 3). Each of the categories is discussed below, with example participant quotes. 
Table 3. Summary of categories, sub-categories and exemplar participant quotes from students' responses to the semi-structured focus group interview

$\begin{array}{lll}\text { Category Subcategory } & \text { Participant quote }\end{array}$

1. Simulation creates Simulation creates opportunities to learn opportunities to widely within a day (2)

learn (15)

Simulation creates opportunities for clinical reasoning (1)

"and it was good as most of them I hadn't had any experience in before either so I was learning stuff from every single simulation" (Participant 2).

"it's nice to be able to have that process of clinical reasoning ... whenever in the future you are presented with that sort of case again you can go through the steps that like I remember because it is a different format than you just going through your notes" (Participant 3).

Simulation creates opportunities to "It was practical ways to improve our clinical skills so not just your knowledge but experiment (1) just like your approaches probably 3 or 4 things that next time I would do this and this differently or I would try this so that was really good" (Participant 4).

Simulation creates opportunities to learn "I have got to say I learnt a lot from watching my peers and just getting strategies from peers (2) from them as well across all simulation activities" (Participant 3).

Simulation provides opportunities to "we are not even guaranteed a full six weeks of adults. It's adults or mixed placement expose students to adult clients (5) because they are so hard to come by and just having this would just help even if you I don't know they could just get you four weeks of adults and if you could somehow you could make up the rest of the hours with a simulated patient would be really really good" (Participant 2).

Simulation accommodates all types of "It is just better for people who are more kinaesthetic learners" (Participant 4).

2. Simulation learners (4)

provides a Simulation allows students to apply “Just like sort of translating your lecture notes into a real situational simulation" theory to practice (3)

beneficial transition for students (20)

Simulation is safe $(2)$ (Participant 4)

"I think the fact that it's a safe learning environment, they get to learn the practical side of the theory but in that safe environment" (Participant 3).

Simulation reduces anxiety and "... it took a lot of anxiety away from me” (Participant 4); "I feel like going into my

increases confidence (4)

Simulation provides practice and an

opportunity for revision (11) adult placement I would be a lot more confident” (Participant 2). "Experience. I haven't had much of a chance to do anything with adults so I am expecting to do that this block placement, so I thought what a good opportunity to get some practice" (Participant 1). 


\section{Category}

3. Simulation provides holistic

reflection and

feedback (12)

\section{Subcategory}

Appreciated feedback from multiple sources (4)

fosters all types and forms of feedback (7)

Simulation feedback allows for fine

4. Students place value on realism on simulation (11)

A realistic environment is key to simulation (3)

Portrayal of cases by simulated patients needs to be realistic (8)

5. Students are Simulation is valued by students (9) invested in simulation (9)

6. Simulation requires consideration of timing and preparation (20)

Preparation time is needed for students

(12)

Timing in simulation is important for students (8) tuning of skills (1)

\section{Participant quote}

“... when we get feedback from an actual standardised patient so like the few that we had today, it is just such a unique and rare opportunity to get honest feedback about how you are going from who the person who is not a speech pathologist which I think is amazing" (Participant 6).

"one of the main reasons for the confidence shooting up because all the feedback was constructive and there was so much positive feedback thrown into there and I have had quite a few experiences where you don't get you don't get the positive feedback and so having all of that positivity was really really good" (Participant 2 ).

"So practising that and then knowing where I need to improve and then taking that away and implementing it into my practice on placement" (Participant 1). "So it was very real in that sense and I appreciated it" (Participant 3).

"I felt that it was a bit off putting when the patient had no impairment whatsoever. I felt that like it didn't feel as real. The doing the assessment didn't feel as real" (Participant 5).

"So worthwhile and valuable. Yeah really valuable" (Participant 3).
"... we would have like 10 minutes at the most or sometimes but it was just enough to kind of get your head around it before we were actually in there" (Participant 2).

"Bit rushed but I mean it just needed to be spread out a bit more. Maybe over a few days or a week or something. Because I just feel like we didn't get much time to sit there and maybe say like all we needed to say" (Participant 1). 


\section{Simulation creates opportunities to learn}

Students commented on the variety of learning activities within the simulation-based learning experience which provided them with ample opportunities to learn: "it wasn't just all at the bedside or all at the clinic table - it was good that we had a variety" (Participant 5). The practical nature of the simulation was also reported to accommodate different learning styles and enable the participants to trial and develop their clinical skills: "It was practical ways to improve our clinical skills so not just your knowledge" (Participant 4). The opportunity to be 'thrown into' the learning experience, and then to have an opportunity to learn, observe, and receive feedback from their peers was another component of simulation that the participants valued. Not all participants felt that there was enough opportunity to develop their clinical reasoning skills however: "I think [what] might have been useful is discussing, having a discussion about clinical reasoning regarding certain patients” (Participant 3).

\section{Simulation provides a beneficial transition for students}

The ability of the simulation to translate knowledge and apply theory to practice within a safe environment were concepts expressed by the students: "the fact that it's a safe learning environment, they get to learn the practical side of the theory but in that safe environment" (Participant 3). The link between conducting physical practice in a safe environment and the reduction of anxiety and increase in confidence levels were also noted: "it took a lot of anxiety away from me" (Participant 4). Students valued the simulation learning approach and introduced the concept of embedding this modality: "I think such a program would be invaluable to the clinical learning of students ... so I think that would be amazing if that could be incorporated into a program" (Participant 3 ).

\section{Simulation provides holistic reflection and feedback}

The connection between holistic reflection and feedback and improved confidence was addressed by the students: "I feel like going into my adult placement I would be a lot more confident just straight off the back and the positive feedback is just huge" (Participant 2). Students also indicated that the simulationbased learning activities were a positive experience particularly focussing on the value of feedback generally: "it is important to know the things that you are doing right so that the things that you are doing not so right you can get feedback" (Participant 3). The application of their improved confidence levels following the simulation-based learning activities when working with an adult population was highlighted: "it was a really really positive experience and so I know that if I am in a hospital and I have to think on my feet I know that I will be ok" (Participant 2).

Receiving feedback from multiple sources including peers, the clinical educator, and the simulated patient was also valued by students as unique to this learning modality: "I really appreciated all of the feedback from the different people... it was really nice to get those different points of view" (Participant 3). It was identified, however, that receiving feedback from the simulated patient in particular was integral: "when we get feedback from an actual standardised patient... it is just such a unique and rare opportunity to get honest feedback ... which I think is amazing" (Participant 6). When asked to reflect on their experience in this study, simulated patient feedback was most highly regarded: "that's what I thought was the best thing about it" (Participant 6).

\section{Students place value on realism on simulation}

Realism within simulation was important for the students. Whilst the students appreciated the re-creation of the hospital setting - "So it was very real in that sense and I appreciated it" (Participant 3) - there was also emphasis placed on the importance of a realistic portrayal of the simulated patients: "I felt that it was a bit off-putting when the patient had no impairment whatsoever. I felt that like it didn't feel as real" (Participant 5). Students felt it was important for their own clinical learning to experience the patient's perspective which was achieved through peer role play opportunities.

\section{Students are invested in simulation}

Positive comments about simulation and the simulated learning program were expressed by students whereby they reported value and direct benefit to themselves and their learning: "So worthwhile and valuable" (Participant 3). Students expressed the need for more simulation opportunities and/or rotational 
sessions within the simulated learning program to gain further experience. Requests were made to expand this simulation-based learning program over the course of the week: "I would still like to do it over a week though I think that would be like a really good experience if it was like a clinic week" (Participant 2); "Bit rushed, it just needed to be spread out a bit more. Maybe over a few days or a week or something” (Participant 1).

\section{Simulation requires consideration of timing and preparation}

With time limited prior to and during the simulation program, the students felt under-prepared so preparation time was valued: "we would have like 10 minutes at the most but it was just enough to kind of get your head around it before we were actually in there" (Participant 2). Despite the request for increased preparation time, the actual timing of the simulation-based learning activities was found to be suitable - "There was plenty of time in the simulation" (Participant 1) - and responded positively: "I didn't mind the timing at all" (Participant 6).

Although there were mixed feelings regarding the intensity of the simulation activities, the students indicated that increased simulation opportunities would be advantageous to their learning: "I just think it would be useful to have a simulation exercise after every sort of unit that we do" (Participant 4). Some students requested direct involvement in all simulated learning activities rather than observing peers - "I would have liked to have the one session that the other two groups had because we didn't really have one by ourselves" (Participant 2) - which is reflective of the limited time available within one day of simulated learning activities. Specifics regarding duration and timing of the one-day simulation-based learning program were discussed: "I just feel like we didn't get much time to sit there and maybe say all we needed to say” (Participant 1).

\section{Discussion}

This pilot study aimed to explore students' perceptions of participating in a one-day simulation experience focussed on adult speech pathology practice. Students reported increased confidence in their skills related to adult areas of speech pathology practice and decreased perceived anxiety levels. These findings concur with those reported in other studies of speech pathology students following simulation experiences (Miles et al., 2016; Rose et al., 2017) and specifically highlight the value of simulation in supporting students' development of skills in working with an adult population. Whilst all students reported previous experience with simulated learning activities throughout their speech pathology program, not all had encountered working with adult clients within their clinical program. The literature has previously shown that speech pathology students are less confident working with adults presenting with communication impairments despite completion of their related coursework (Finch et al., 2013). Furthermore, within the health field it has been reported that limited opportunities to experience the acute-setting environment negatively impacted students' confidence and anxiety levels (Blackstock et al., 2013). In this pilot study, students' perceptions regarding their skills, confidence and anxiety levels when working with a simulated adult caseload supports further consideration of using simulation-based learning activities within speech pathology program curricula.

In previous research, students have reported reduced confidence and increased anxiety during interactions on clinical placements (Finch et al. 2013; Hill et al., 2013; Lee \& Schmaman, 1987; Rose et al., 2017). In the current study, students perceived that their confidence improved in interaction skills, including interacting with other professionals, clients and family members, as well as providing feedback to peers. In accordance with best practice simulated learning (Ker \& Bradley, 2014), students were provided with an opportunity to practise, obtain feedback and then repeat critical speech pathology practice skills, such as how to approach a client within their environment, as well as develop rapport and interact in a professional manner. Students also highlighted the importance of positive feedback. It is likely that the inclusion of feedback contributed to their perception of increased confidence levels. Similar outcomes of student perceptions regarding increased skill levels have been reported in earlier speech pathology research (Hill et al., 2013; Rose et al., 2017), although these studies did not explore a broad range of clinical skills and environments within an adult practice context.

In addition to students gaining confidence in their clinical skills when working with adult clients, survey and focus-group data also indicated decreased levels of anxiety. Reduced perceived anxiety levels may be related to the students' previous exposure to simulation-based learning activities throughout their program 
prior to this study, a notion supported by previous research in nursing (Howard et al., 2011). However, lowered anxiety levels following a simulation activity have been reported in the literature for nursing students (Gore et al., 2011), speech pathology students (Hill et al., 2013; Rose et al., 2017; Ward et al., 2015) and speech pathologists (Ward et al., 2014), suggesting a direct relationship between students' anxiety and the one-day simulation experience in the current study. Further research could explore students' differing levels of anxiety and possible causes.

Integrated data drawn from the student survey and focus group highlighted key aspects of the learning experience. Students involved in this pilot study indicated on the SSE scale (Levett-Jones et al., 2011) that the simulation was an overall valuable learning experience. Rose et al.'s (2017) study reported similar results with speech pathology students engaging in an acute simulated learning environment, and Hill et al. (2013) reported students' appreciation of simulation as a learning modality. Translating theory to practice within a safe environment was noted by the participants to be a key advantage to these simulation-based learning activities. Application of theory into 'real-life' clinical examples was highlighted as important for increased confidence and reduced anxiety levels. The process of doing the activity within a safe space was expressed and appreciated in this study as a beneficial transition for student learning. Making connections between theory and practice and essentially bridging that gap has been identified and supported in previous simulation research (Jeffries, 2005; Ogilvie et al., 2011; Ward et al., 2014). The importance of active learning that is evident in students' experiences in simulation is supported by constructivist learning theory (Mayer, 2004) enabling learning to be student-led (Lateef, 2010).

Students reported lower median scores on the clinical reasoning and clinical decision-making skills items on the SSE scale (Levett-Jones et al., 2011) and some commented that this was not enough opportunity to develop their skills in these areas. Given this and the fact that students reported time constraints of the learning activities across one day in this study, the results of this study support the development and evaluation of a longer simulation-based learning program. Simulation activities that enable more opportunities for clinical reasoning and other related clinical skills may enhance the findings from the current study. Importantly, this study has found that students value simulation as an opportunity to develop clinical skills in a safe, education-rich environment which is supported by previous literature in speech pathology simulation (Hill et al., 2013; Rose et al., 2017; Ward et al., 2015).

\section{Limitations and future directions}

As this is a pilot study of the perceptions and experience of one group of students, results should be interpreted cautiously and the sample may not be representative of all students. The participants in this study were volunteer students who completed the simulated learning program as an additional learning opportunity within the final year of their program and were therefore not assessed on their performance. The assessment component of any learning task may influence students' engagement and/or their response to perception ratings of confidence and anxiety.

Whilst the pilot study has inherent limitations, these preliminary findings support the development and rigorous evaluation of simulation-based learning experiences in speech pathology. Additionally, it would be beneficial to further determine differences in anxiety levels and impact on clinical learning in other simulated learning environments for students.

\section{Conclusion}

This pilot study demonstrated that simulation-based learning for adult areas of speech pathology practice has a role within speech pathology curricula. Students benefited from this simulation experience and indicated that it was a valuable and worthwhile addition to their learning. The value of applying theoretical knowledge into practice was perceived to increase confidence levels across both clinical skills and knowledge with a reduction of anxiety levels. Additionally, the opportunity to receive a broad range of feedback was highlighted as unique to simulation. Further research is required to determine learning outcomes from a longer, more intensive simulation program. 


\section{Acknowledgements}

The authors would like to thank the student participants, Professor Elizabeth Ward and Ms Daniella Cain for their contribution to this research study for their contribution to this research study.

\section{ORCID}

Adriana Penman http://orcid.org/0000-0003-0488-6788

Anne E. Hill http://orcid.org/0000-0002-6272-9433

Sally Hewat http://orcid.org/0000-0002-7043-7086

Nerina Scarinci http://orcid.org/0000-0002-1457-6663

\section{References}

Barrows, H. (1993). An overview of the uses of standardized patients for teaching and evaluating clinical skills. Academic Medicine, 68(6), 443-453. https://doi.org/10.1097/00001888-199306000-00002

Blackstock, F. C., Watson, K. M., Morris, N. R., Jones, A., Wright, A., McMeeken, J. M., Rivett, D.A., O’Connor, V., Peterson, R. F., Haines, T. P., Watson, G., \& Jull, G. A. (2013). Simulation can contribute a part of cardiorespiratory physiotherapy clinical education. Simulation in Healthcare, 8(1), 32-42. https://doi.org/10.1097/SIH.0b013e318273101a

Creswell, J. W., \& Plano Clark, V. L. (2011). Designing and conducting mixed methods research (2nd ed.). Sage.

Dudding, C. C., \& Nottingham, E. E. (2018). A national survey of simulation use in university programs in communication sciences and disorders. American Journal of Speech-Language Pathology, 27(1), 71-81. https://doi.org/10.1044/2017_AJSLP-17-0015

Fenwick, T., \& Dahlgren, M. A. (2015). Towards socio-material approaches in simulation-based education: Lessons from complexity theory. Medical Education, 49(4), 359-367. https://doi.org/10.1111/medu.12638

Finch, E., Fleming, J., Brown, K., Lethlean, J., Cameron, A., \& McPhail, S. (2013). The confidence of speech-language pathology students regarding communicating with people with aphasia. $B M C$ Medical Education, 13(1), 92.

Gore, T., Hunt, C., Parker, F., \& Raines, K. (2011). The effects of simulated clinical experience on anxiety: Nursing students' perspectives. Clinical Simulation in Nursing, 7(5), e175-e180. https://doi.org/10.1016/j.ecns.2010.02.001

Graneheim, U. H., \& Lundman, B. (2004). Qualitative content analysis in nursing research: Concepts, procedures and measures to achieve trustworthiness. Nurse Education Today, 24(2), 105-112. https://doi.org/10.1016/j.nedt.2003.10.001

Hayden, J., Smiley, R., Alexander, M., Kardong-Edgren, S., \& Jeffries, P. (2014). The NCSBN national simulation study: A longitudinal, randomized, controlled study replacing clinical hours with simulation in prelicensure nursing education. Journal of Nursing Regulation, 5(2), S3-S40. https://doi.org/10.1016/S2155-8256(15)30062-4

Health Workforce Australia. (2014). Australia's health workforce series: Speech pathologists in focus. Health Workforce Australia.

Hewat, S., Penman, A., Davidson, B., Baldac, S., Howells, S., Walters, J., Purcell, A., Cardell, E., McCabe, P., Caird, E., Ward, E.C., \& Hill, A.E. (in press). A framework to support development 
of quality simulation-based learning programs in speech-language pathology. International Journal of Language and Communication Disorders

Higgs, J., \& Titchen, A. (2001). Rethinking the practice-knowledge interface in an uncertain world: a model for practice development. British Journal of Occupational Therapy, 64(11), 526-533.

Hill, A. E, Davidson, B. J., \& Theodoros, D. G. (2010). A review of standardized patients in clinical education: Implications for speech-language pathology programs. International Journal of Speech-Language Pathology, 12(3), 259-270. https://doi.org/10.3109/17549500903082445

Hill, A. E., Davidson, B. J., \& Theodoros, D. G. (2013). Speech-language pathology students' perceptions of a standardised patient clinic. Journal of Allied Health, 42(2), 84-91.

Howard, V., Englert, N., Kameg, K., \& Perozzi, K. (2011). Integration of simulation across the undergraduate curriculum: Student and faculty perspectives. Clinical Simulation in Nursing, 7(1), e1-e10. https://doi.org/10.1016/j.ecns.2009.10.004

Jeffries, P. R. (2005). A framework for designing, implementing, and evaluating simulations used as teaching strategies in nursing. Nursing Education Perspectives, 26(2), 96-103.

Kelly, M. A., Hopwood, N., Rooney, D., \& Boud, D. (2016). Enhancing students' learning through simulation: Dealing with diverse, large cohorts. Clinical Simulation in Nursing, 12(5), 171-176. https://doi.org/10.1016/j.ecns.2016.01.010

Ker, J., \& Bradley, P. (2014). Simulation in medical education. In T. Swanwick (Ed.), Understanding medical education: Evidence, theory and practice (2nd ed.). Wiley Blackwell.

Khan, M. E., Anker, M., Patel, B. C., Barge, S., Sadhwani, H., \& Kohle, R. (1991). The use of focus groups in social and behavioural research: Some methodological issues. World Health Statistics Quarterly, 44(3), 145-149.

Kolb, A. Y., \& Kolb, D. A. (2005). Learning styles and learning spaces: Enhancing experiential learning in higher education. Academy of Management Learning \& Education, 4(2), 193-212. https://doi.org/10.5465/AMLE.2005.17268566

Lateef, F. (2010). Simulation-based learning: Just like the real thing. Journal of Emergencies, Trauma, and Shock, 3(4), 348-352. https://doi.org/10.4103/0974-2700.70743

Lee, C., \& Schmaman, F. (1987). Self-efficacy as a predictor of clinical skills among speech pathology students. Higher Education, 16, 407-416.

Levett-Jones, T., McCoy, M., Lapkin, S., Noble, D., Hoffman, K., Dempsey J., Arthur, C., Roche, J. (2011). The development and psychometric testing of the Satisfaction with Simulation Experience scale. Nurse Education Today, 31(7), 705-710.

https://doi.org/10.1016/j.nedt.2011.01.004

MacBean, N., Theodoros, D. G., Davidson, B. J., \& Hill, A. E. (2013). Simulated learning environments in speech-language pathology: An Australian response. International Journal of SpeechLanguage Pathology, 15(3), 345-357. https://doi.org/10.3109/17549507.2013.779024

Mayer, R. (2004). Should there be a three-strikes rule against pure discovery learning? The case for guided methods of instruction. American Psychologist, 59(1), 14-19.

https://doi.org/10.1037/0003-066x.59.1.14

Meakim, C., Boese, T., Decker, S., Franklin, A. E., Gloe, D, Lioce, L., Sando, C., \& Borum, J. C. (2013). Standards of best practice: Simulation standard I: Terminology. Clinical Simulation in Nursing, 9(6), S3-S11. https://doi.org/10.1016/j.ecns.2013.04.001 
Miles, A., Friary, P., Jackson, B., Sekula, J., \& Braakhuis, A. (2016). Simulation-based dysphagia training: Teaching interprofessional clinical reasoning in a hospital environment. Dysphagia, 31(3), 407-415. https://doi.org/10.1007/s00455-016-9691-0

Nestel, D., \& Bearman, M. (2014). Simulated patient methodology: Theory, evidence and practice. Wiley Blackwell.

Ogilvie, S., Cragg, B., \& Foulds, B. (2011). Perceptions of nursing students on the process and outcomes of a simulation experience. Nurse Educator, 36(2), 56-58. https://doi.org/10.1097/NNE.0b013e31820b4fd5

Page-Cutrara, K., \& Turk, M. (2017). Impact of prebriefing on competency performance, clinical judgment and experience in simulation: An experimental study. Nurse Education Today, 48, 7883. https://doi.org/10.1016/j.nedt.2016.09.012

Rose, T. A., Copley, A., \& Scarinci, N. A. (2017). Benefits of providing an acute simulated learning environment to speech pathology students: An exploratory study. Focus on Health Professional Education: A Multi-disciplinary Journal, 18(3), 44-59. https://doi.org/10.11157/fohpe.v18i3.186

Sheepway, L., Lincoln, M., \& Togher, L. (2011). An international study of clinical education practices in speech-language pathology. International Journal of Speech-Language Pathology, 13(2), 174185. https://doi.org/10.3109/17549507.2011.491129

Speech Pathology Association of Australia. (SPAA). (2010). What is a speech pathologist? The Speech Pathology Association of Australia.

Speech Pathology Association of Australia. (SPAA). (2011). Competency-Based Occupational Standards (CBOS) for Speech Pathologists: Entry-Level (revised). The Speech Pathology Association of Australia.

Speech Pathology Australia. (2018). Clinical Education in Australia: Building a Profession for the Future. Melbourne: SPA. https://www.speechpathologyaustralia.org.au/

Wallace, D., \& Moughrabi, S. (2016). The efficacy of simulation debriefing in developing critical thinkning in accelerated baccalaureate nursing students. Journal of Nursing Education and Practice, 6(5), 13-18. https://doi.org/10.5430/jnep.v6n5p13

Ward, E. C., Baker, S. C., Wall, L. R., Duggan, B. L. J., Hancock, K. L., Bassett, L. V., \& Hyde, T. J. (2014). Can human mannequin-based simulation provide a feasible and clinically acceptable method for training tracheostomy management skills for speech-language pathologists?. American Journal of Speech-Language Pathology, 23(3), 421-436. https://doi.org/10.1044/2014_AJSLP-13-0050

Ward, E. C., Hill, A. E., Nund, R. L., Rumbach, A. F., Walker-Smith, K., Wright, S. E., Kelly, K., \& Dodrill, P. (2015). Developing clinical skills for paediatric dysphagia management using Human Patient Simulation (HPS). International Journal of Speech-Language Pathology, 17(3), 230 240. https://doi.org/10.3109/17549507.2015.1025846

Watson, K., Wright, A., Morris, N., McMeeken, J., Rivett, D., Blackstock, F., Jones, A., Haines, T., O'Connor, V., Watson, G., Peterson, R., \& Jull, G.A. (2012). Can simulation replace part of clinical time? Two parallel randomised controlled trials. Medical Education, 46(7), 657-667. https://doi.org/10.1111/j.1365-2923.2012.04295.x 